\title{
Experimental Results of Siloxanes Rubber Reinforced with Magnetic Fillers Used to Protect the Uman Factor to Electromagnetic Radiation
}

\author{
ELENA VALENTINA STOIAN, J ANA PINTEA², MARIA CRISTIANA ENESCU1*, CARMEN OTILIA RUSANESCU³ \\ 'Valahia University of Targoviste, Faculty of Materials Engineering and Mechanics, 12 Sinaia Alley, 130004, Targoviste, Romania \\ ${ }^{2}$ National Institute for Research and Development in Electrical Engineering - ICPE-CA, 313 Splaiul Unirii, 030138, Bucharest, \\ Romania \\ ${ }^{3}$ Valahia University of Targoviste, Faculty of Materials Engineering and Mechanics, 12 Sinaia Alley, Targoviste, Romania \\ ${ }^{3}$ Politehnica University of Bucharest, Faculty of Biotechnical Systems Engineering, 313 Splaiul Independentei, 060042, Bucharest, \\ Romania
}

The character of the original paper is to provide electromagnetic radiation absorbing material that attenuation characteristics of the electromagnetic field very good, as compared to the absorbent materials studied to date. This paper presents results of research on processing, characterization and behavior of composite materials based on silicone rubber used for electromagnetic shielding. In this work silicone rubbers is reinforced with magnetic fillers (iron silicon). The obtaining of composite materials was with the aid of a doctor blade technique. Doctor blade technique is a coating technique widely used for producing thin films on large area surfaces. The samples were processed in the laboratory using a plated nettling (PN), that was impregnated with a silicone rubber based composite containing powder of iron silicon (SI). Were achieved measurements of the both parts of the materials obtaining. These have shown an electromagnetic shielding effectiveness the order of 3.35-41.62 dB (white face) and 3.53-41.42 dB (gray face), in 1-18 GHz frequency range according to SR EN 50 147-1:1999. The paper tries to identify an absorbent material with the ability to protecthuman beings of electromagnetic radiation that surround us every day and everymoment. With the exponential increase in development of commercial, aerospace, military and scientific electronic devices in modern society, electromagnetic radiation is becoming the fourth public pollution after the air, water and noise ones.

\section{Keywords: Eeco-friendly materials, composites, thin layers, magnetic fillers}

The use of polymer blends is an effective method for altering the performance of polymer materials and is widely employed in engineering plastics, rubber, and fiber materials. Elastomeric blends are used for many reasons such as lowering the compound cost, for ease of fabrication and to improve the performance of the industrial rubber. The term rubber (elastomer) is used to describe vulcanized polymeric materials, whose glass transition temperature is sub-ambient and, amongst other properties, has the ability to be extensively and on release of stress, return to its original length The common characteristics of elastomers are their elasticity, flexibility, and toughness.

Beyond these common characteristics, each rubber has its own unique properties, often requiring additives to achieve the appropriate behaviors. It is customary when discussing the formulation of rubber compounds to classify the additives by the function they serve. Rubber compounding ingredients can be categorized as: vulcanizing or crosslinking agents, processing aids, fillers, antidegradants, plasticizers and other specialty additives [1-4].

The most common advanced composites are polymer matrix composites. Elastomer consist of a polymer thermoplastic or thermosetting reinforced by filler (iron silicon). These materials can be fashioned into a variable shapes and sizes. The reason for these being mostcommon is their low cost, high strength and simple manufacturing principles [5].

The domains of use of the composite materials were developed with the time and obtaining some specific technologies, remarking: the equipment in the process industry [6], in the aeronautic industry, in the ground or underwater transport industry, in the military industry, in the healthcare domain to reduce the electromagnetic interference like absorbing materials [7-28]. Silicones are polymers containing silicon, togheter with the carbon, hydrogen, oxygen, and sometimes other elements [29].

In order to avoid these hazard to human being and to protect the sensitive circuits from undesired electromagnetic radiation, electromagnetic shielding is essential. The electromagnetic wave consists of electric field $(\mathrm{E})$ and magnetic field $(\mathrm{H})$ wich are oscillating phse perpendicular to each other and also perpendicular to the direction of energy propagation. These electric and magnetic fields can be arrested by means of reflection or absorbtion [30,31].

\section{Experimental part}

Materials and methods

Rhodorsil RTV 3221 (room temperature vulcanization crosslinking occurs at room temperature) was selected as the polymer matrix due to its common use in microelectronics and micro machining, well-known processing conditions, low cost, good mechanical and thermal properties.

Was used pow der iron silicon up to $0.02 \%$ carbon, up to $0.1 \%$ aluminum, $0.04 \%$ phosphorus and $002 \%$ maximum sulfur, with the size of grain $115[\mu \mathrm{m}]$, from S.C. Hoeganaes Buzau. The materials were processed in laboratory, containing a plated nettling, which has been impregnated with a matrix of a composite material based on siloxane rubber containing iron silicon pow der as reinforcing filler.

Thus, we started from a plated nettling, abbreviated PN. The net was then coated with a siloxane rubber mixture and pow der of iron silicon abreviated PNSSI. The powder (iron silicon-SI) have been dispersed into polymeric matrix -silicone rubber. Mixing has been made at the room temperature. Carrying out composites has been made by laying mixtures on the plated nettling (PN) by means of doctor blade technique. The following abbreviations/

*email: cristiana_enescu@yahoo.com; Phone: 0721187207 
acronyms, such as PNSSI means polymeric mixture of siloxanic rubber and iron silicon powder laid on the plated nettling and SSI is polymeric mixture with silicon rubber and iron silicon without laying on plated nettling .

The thickness of the test samples was $3 \mathrm{~mm}$, and the thickness of the plated nettling used to make the composites was $0.25 \mathrm{~mm}$.

Figure 1 represents the composite matrix siloxane rubber and iron -silicon powder settling of on one side of the plated nettling (named PNSSI ).

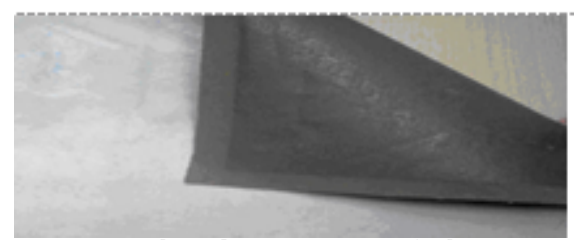

Fig.1 Settling down mixture of siloxanic rubber - iron-silicon on only face of plated nettling (PNSSI)

From figures 2, 3 and 4 can we see a big difference between the two sides of the composite matrix siloxane rubber and iron powder - silicon. Due to high density of powder iron silicon, this tends to settle of the bottom of the capsule, which is why when the composite material is spread with a spatula, layer on the lower level is so rich in powder of iron silicon and the other side is poorest in this powder.

Fig.2 Laying of siloxanic rubber and ironsilicon mixture without plated nettling (SSIwhite face)

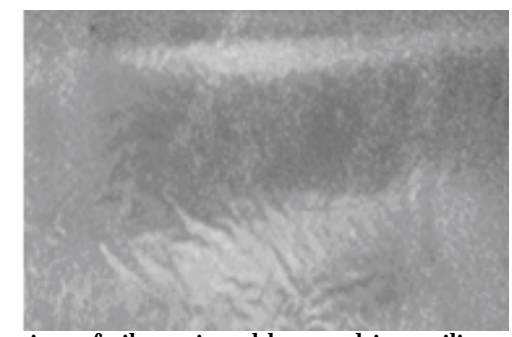

Fig.3 Laying of siloxanic rubber and iron silicon without plated nettling (SSI- gray face)

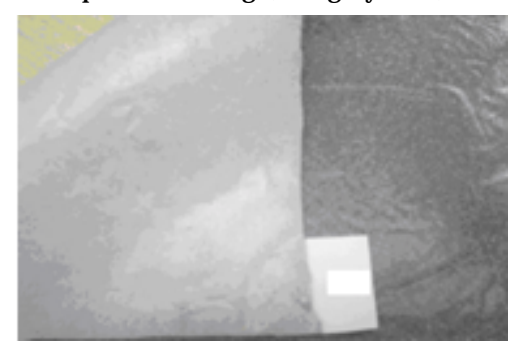

Fig.4 View of both sides of the composite matrix siloxane rubber and iron powder - silicon

\section{Results and discussions}

\section{$X$-ray diffraction}

For analysis Difractometer D8 ADVANCE of AXS Bruker type has been used (anodic tube used was of molybdenum) with pass of $0.04^{0}$; scanning speed $1 \mathrm{~s} /$ pass; scanning has been achieved between $10^{\circ}-100^{\circ}(2 \theta)$.

According diffractometry 5 , peaks have maximum intensity for silicon oxide $12.34^{\circ}, 16.77^{\circ}$ for $\mathrm{FeS}_{2}$, iron at $20.11^{\circ}$, and for $\mathrm{Fe}_{3} \mathrm{Si}$ the maximum diffraction peak is at the angle of $35.78^{\circ}$. According to records of indexes files, $\mathrm{FeS}_{2} \mathrm{Fe}_{3} \mathrm{Si}$ crystallizes in cubic system, and silicon oxide crystallizes in the tetragonal system.

Diffractometry 6 phase shows that is a majority proportion of silicon oxide and a the minority phase is represented by iron. According to index files, note that the maximum of diffraction peaks for iron oxide is at an angle of $10,12^{\circ}$ compound wich crystallize in hexagonal system and iron has the maximum peak value of the angle is $19,88^{\circ}$ and the iron crystallize in the cubic system.

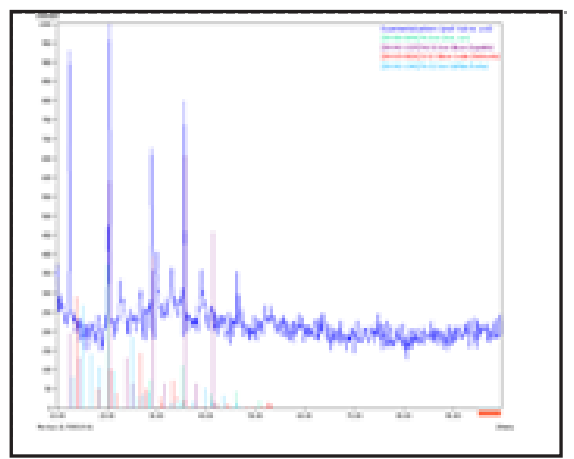

Fig.5 PNSSI diffractogram

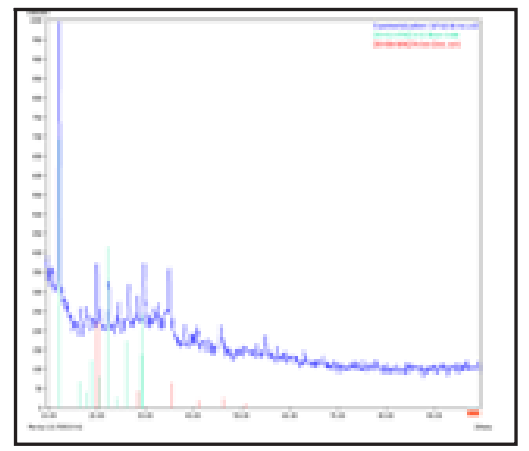

Fig.6 SSI difractogram

\section{Optic microscopy}

The microscopic analyses have been carried out with NU2 Carl Zeiss Jena Germany microprobe 1:700 with reflected light in lightening field using the metallographic light system and plane chromated objective $25 x$, usable in polarized light, too. Images have been digitally achieved by means of a video camera of power up to 500x.
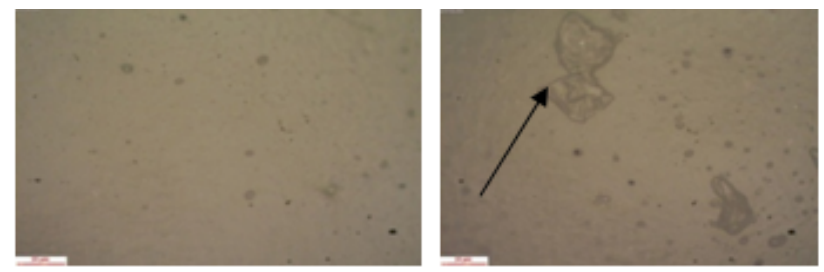

Fig. 7 Microscopy of composite material PNSSI (withe face) magnitude $500 \mathrm{x}$

Figure 7 shows agglomerates of the composite material, as well as certain porosities, scratches. These occur due to the manual technique used of stretching the composite material on the plated nettling. Since the composite material front is poorer in silicon iron powder, however, according to figure 8, a small amount of powder.

Analyzing the microscopy (fig. 8) the gray part of the composite material (the richer part in silicon iron powder) we identify the silicon iron powder very well. It also sees 

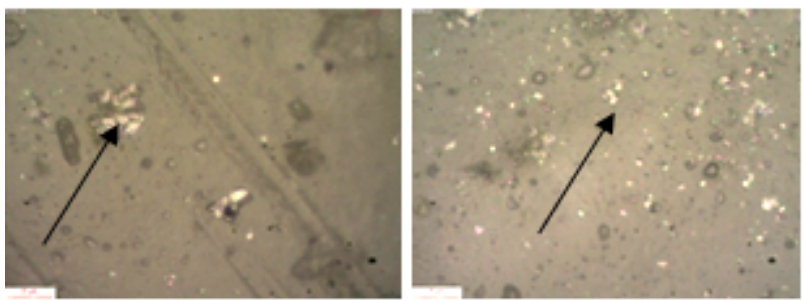

Fig. 8 Microscopy of composite material PNSSI (gray face) magnitude $500 x$

scratches due to the technique used. In this microscopy, iron pow der is present in a larger amount than in figure 7.

Figures 9 and 10 shows the microscopy of the composite material not coated on the plated nettling. At the same time, we can see the silicon iron pow der through the yellow patch (fig. 9). It also identifies scratches and agglomerations of material, possibly due to a homogenization inadequate.
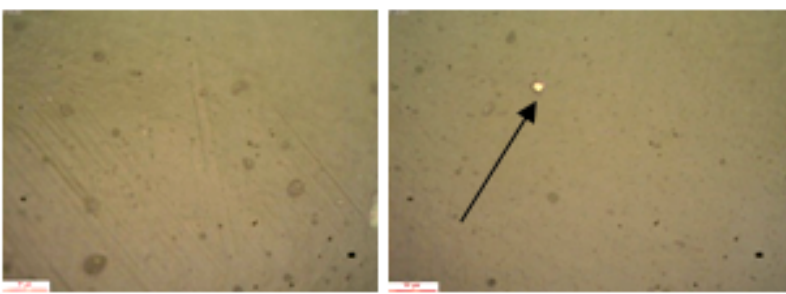

Fig. 9 Microscopy of composite material SSI (white face) magnitude $500 x$
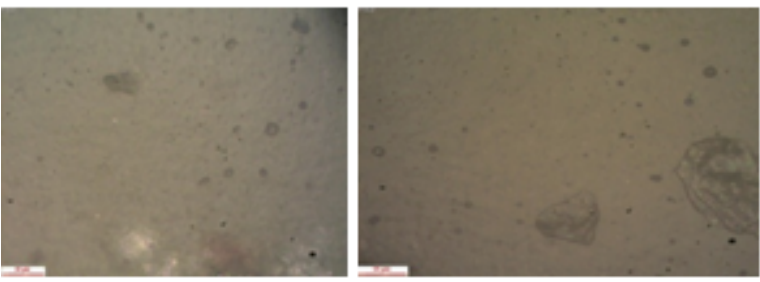

Fig. 10 Microscopy of composite material SSI (gray face) magnitude $500 x$

Measurements of transmission diminishing in frequencies range $1-18 \mathrm{GHz}$

The analysis goal is to determine the radio transmission diminishing in frequencies range $1-18 \mathrm{GHz}$, with a view to establishing applicability field of composite materials with polymeric matrix obtained. The method principle consists in the diminishing measurement of radio transmission chain in two situation: without material and with the material inserted on the transmission chain. The transmission chain can be free space or waves guide.

Samples were characterized dimensions of $350 \times 350$ $\times 3 \mathrm{~mm}$, and the temperature measurement tests were conducted to mitigate the material was $24^{\circ} \mathrm{C}$. Tests were conducted according to EN 50 147-1:1999 and PI-02 INCDIE ICPE-CA Bucharest.

Electromagnetic waves are emitted by the source (signal generator as type E AGILENT 8257D), pass through the electromagnetic shield (sample), some of them are reflected and absorbed by the shield, and only a fraction is transmitted and received by probe (Horn antenna) placed behind the shield, according figure 11. Spectrum analyzer directly measures the electromagnetic radiations attenuation in decibels $(\mathrm{dB})$.

Shielding effectiveness is determined from equation 1 ,

$$
S E \quad-20 \log \left(\frac{E_{1}}{E_{2}}\right)
$$

where $E_{1}$ is the field strength measured without sample and $E_{2}$ is the field strength measured with the sample mounted on window.

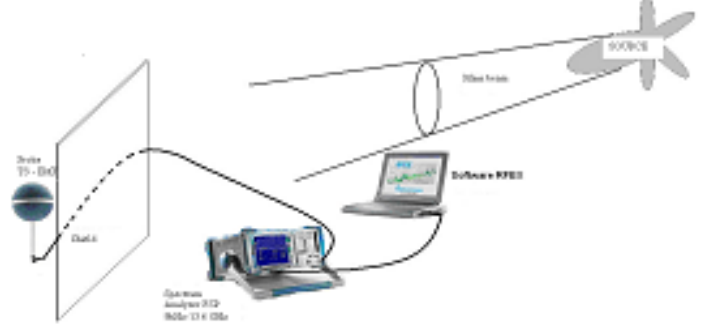

Fig. 11 The diagram for measuring the attenuation

Experimental results of transmission diminishing measurements in the 1-18 GHz broad cast carried on polymer composite PNSSI and SSI, are represented in figure $12-15$.

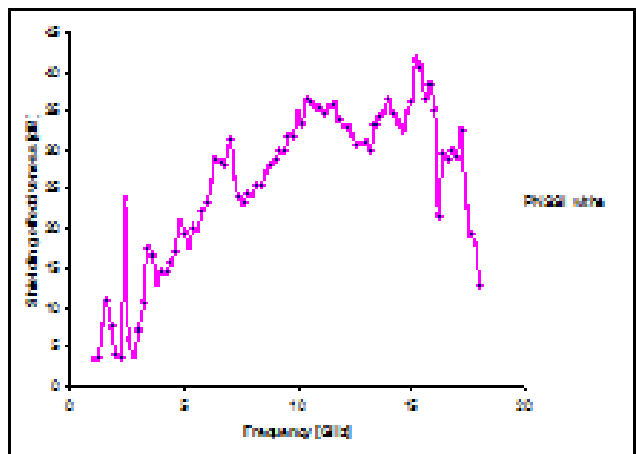

Fig. 12 Shielding effectiveness for PNSSI sample (withe face)

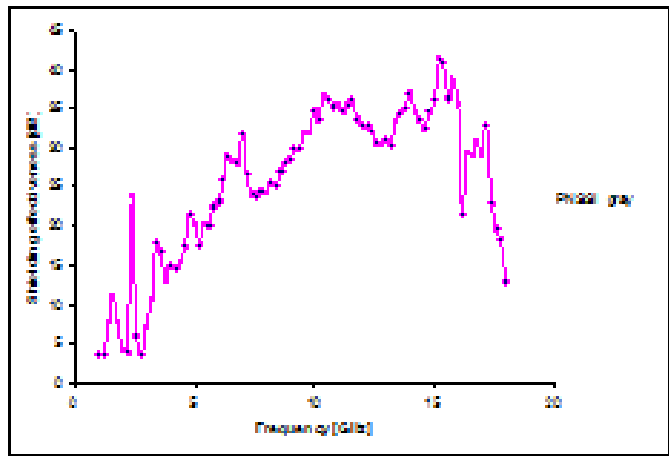

Fig. 13 Shielding effectiveness for PNSSI sample (gray face)

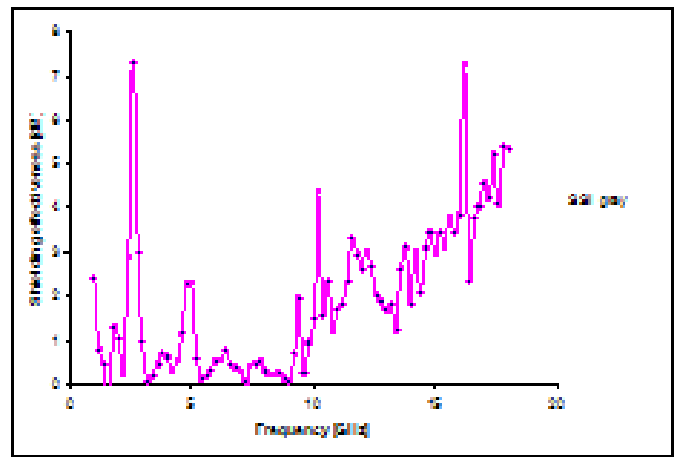

Fig. 14 Shielding effectiveness for SSI sample (gray face)

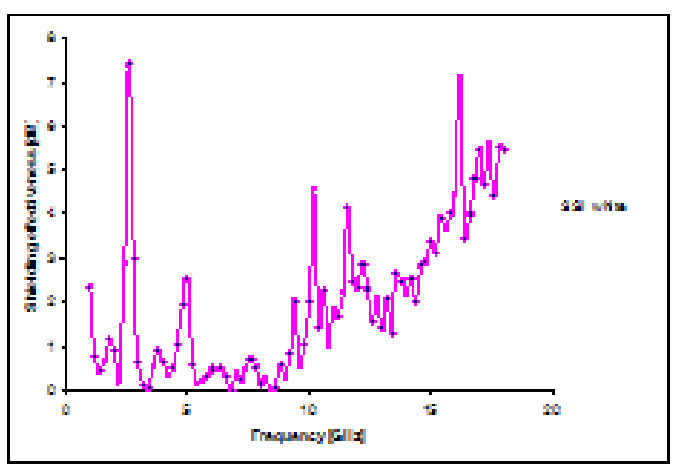

Fig.15 Shielding effectiveness for SSI sample (white face) 
PNSSI composite material was analyzed on both sides (figs. 12 and 13), ie front and back (verso). I noticed with the naked eye that the iron powder after mixing silicon tends to be deposited on the bottom of the material being analyzed, remaining above the poorest powder. Being analized the two sides of the material we found that the level of atenuation is low for white face (fig. 12), compared to the gray face which have a maximum attenuation by $41.42 \mathrm{~dB}$ (fig. 13).

As figure 12 , see, the behaviour of composite system with polymeric matrix (white face) performs minim values of radio diminishing (maximum of transparency) of (3.35) $\mathrm{dB}$ at a frequency of $1 \mathrm{GHz}$ for system PNSSI and the maxim value of radio diminishing is presented by the same composite material at a frequency of $15.2 \mathrm{GHz}$ corresponding to value of $41.62 \mathrm{~dB}$, and the average attenuation of material being analyzed by $24.40 \mathrm{~dB}$.

As figure 13, see, the behaviour of composite system with polymeric matrix (gray face) performs minim values of radio diminishing (maximum of transparency) of (3.53) $\mathrm{dB}$ at a frequency of $1 \mathrm{GHz}$ for system PNSSI and the maxim value of radio diminishing is presented by the same composite material at a frequency of $15.2 \mathrm{GHz}$ corresponding to value of $41.42 \mathrm{~dB}$. The average attenuation material being analyzed by $24.81 \mathrm{~dB}$.

Compared to SSI white face, the SSI gray face (fig. 14) shows values above $2 \mathrm{~dB}$ in the frequency range (11-18) $\mathrm{GHz}$, the maximum attenuation being $5.33 \mathrm{~dB}$ at the 18 $\mathrm{GHz}$ frequency. The maximum attenuation by transmission for SSI gray face is $0.1 \mathrm{~dB}$ less than the SSI white face, ie $7.29 \mathrm{~dB}$. The SSI gray face material has a maximum transparency (minimum attenuation) of $0.06 \mathrm{~dB}$ at the frequency of $9 \mathrm{GHz}$ and a maximum attenuation value of $7.29 \mathrm{~dB}$ at the frequency of $2.6 \mathrm{GHz}$, the average attenuation value for this material being $1.58 \mathrm{~dB}$.

For the material SSI whitouth plated nettling (fig. 15), maximum of transparency is of $(0.058) \mathrm{dB}$ at a frequency $8.6 \mathrm{GHz}$, and the minim values of radio diminishing is (7.39) $\mathrm{dB}$ at a frequency $2.6 \mathrm{GHz}$. The average attenuation of material being analyzed by $2.11 \mathrm{~dB}$.

\section{Relative permittivity}

Measurements were made using the impedance analyzer as type 4294A, the Agilent technology (it is intended to measure the impedance, the relative complex permittivity of dielectric materials and the relative magnetic permeability of magnetic materials and the test fixture 16451B (fixation test used to assess the materials dielectric capacity accurately).

Analyzer is used to measure the dielectric materials in accordance with ASTM D150, for frequencies between $40 \mathrm{~Hz}$ and $30 \mathrm{MHz} .16451 \mathrm{~B}$ uses the plane electrodes method parallel to material introduced between electrodes.

It is measured the complex permittivity, the actual part of composite materials obtained at different values of the work frequencies range (between $40 \mathrm{~Hz}$ and $30 \mathrm{MHz}$ ).

According to figure 16, we see that for sample PNSSI, increasing frequencyleads to values of relative permittivity lowers. The value of permittivity stabilizes on a narrow plateau values of between 4.97-4.76 (the red curve). Permittivity decreases with increasing frequency.

For the material represented by siloxane rubber and iron silicon (SSI), like addition fillers, we find that the permittivity has values between 3.5 and 3.1, minimum value we found it to maximum frequency of $30 \mathrm{MHz}$. The average value is 3.3 (the blue curve). In case of sample SSI the dielectric behavior of the material is good, which confirms the dielectric character of the polymer, in particular the silicone rubber.

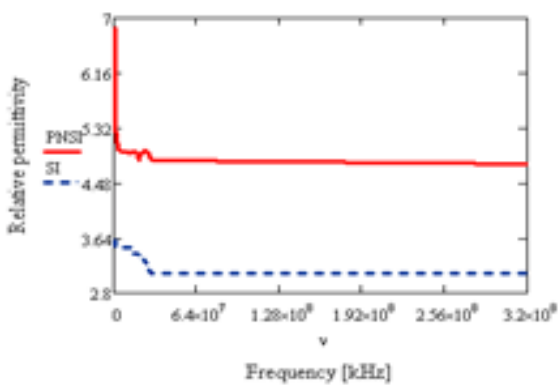

Fig.16 Relative permittivity depending on the frequency for the samples PNSSI and SSIFig. 8 Microscopy of composite material

PNSSI (gray face) - magnitude 500x

We found that with increasing frequency, the measured attenuation grow up to $15 \mathrm{GHz}$ frequency and then decreases with increasing frequency attenuation.

For the material SSI without plated nettling (fig. 14), maximum of transparency of (0.06) dB at a frequency 9 $\mathrm{GHz}$, and the minim values of radio diminishing is (7.29) $\mathrm{dB}$ at a frequency $2.6 \mathrm{GHz}$. The average attenuation material being analyzed by $1.58 \mathrm{~dB}$.

Compared to SSI white face, SSI gray face (fig.14) shows values of $2 \mathrm{~dB}$ over the frequency range (11-18) $\mathrm{GHz}$, the maximum attenuation of $5.33 \mathrm{~dB}$ at the frequency of 18 $\mathrm{GHz}$. The maximum attenuation of gray face is with $0.1 \mathrm{~dB}$ lower than the SSI white face, ie $7.29 \mathrm{~dB}$.

An important feature of the obtained materials is that they generally behave like transparent materials wide frequency fields, such as materials without plated nettling.

Composite materials are stretched over a plated nettling, presents elevated transmission mitigate what makes them fall in effective materials group in terms of filtering electromagnetic radiation.

Compared to the composite materials with an ash dust analysis analyzed from the point of view of electromagnetic attenuation [15, 32, 33], which exhibited maximum attenuation of $45.15 \mathrm{~dB}$, and with the nanocarbon powder composite materials exhibiting maximum attenuation $44.74 \mathrm{~dB}$. The materials analyzed are close to them, and are effective for the intended purpose.

\section{Conclusions}

The main objectives of this work were achieved through cost technique for producing electromagnetic radiation absorbent material with outstanding features, high electrical conductivity, a low dielectric constant and attenuation of the electromagnetic field very good material used for shielding against electromagnetic waves in order to protect the human factor. Materials processing technique is a technique proposed eco no negative impact on the work environment and, in general, the environment, thus contributing to its conservation.

In conclusion, the practical implementation of composite thin films through a cheap and easy method to achieve dispersion of particulate polymeric matrix through a green technique and without environmental impact and low cost materials can be obtained efficiently by using materials that distribution of material properties is not uniform in whole domain, ie type composite materials.

Thin layers thus obtained are flexible, lightweight and can be processed in different thicknesses.

According to the recomandations specific for textiles used in electromagnetic shileding, Electromagnetic Shileding Document Specified Requirements of Textiles, FTTS-FA-003, published in september 2003 and revised in march 2005, it presents two classes of material , namely: Class I - class of professional use materials which include: 
materials for medical equipment, materials for making uniforms for security human factor against waves emitted by electronic devices, and other applications and Class II - class of materials for general use, including textile usual uniform of office, maternity dresses (aprons for pregnant women), electromagnetic radiation protection aprons.

So, we can conclude that the PNSSI with $41.62 \mathrm{~dB}$ (white face) and $41.42 \mathrm{~dB}$ (gray face), are good materials fall into the category of professional use as materials for effective shielding. The electromagnetic shielding percentage offered by these materials is $99.99 \%$. The composite material SSI (white face) with attenuation $7.39 \mathrm{~dB}$ and the material SSI (gray face) with atenuation $7.29 \mathrm{~dB}$, is a very weak material, electromagnetic shielding offered him the percentage is between 70.0 to $80.0 \%$.

From the point of view of the relative permittivity, it is observed for the analyzed samples that, as the frequency increases, the value of permittivity decreases.

For both sides of the material values are low relative permittivity, which means they are good electromagnetic shielding, so the materials are suitable for be used in the intended purpose.

Therefore, the analyzed materials are recommended to be used at low frequencies as electromagnetic radiation absorbing materials.

The effect of adding iron powder silicon in the siloxane rubber, in order to obtain composite materials that protect human factor, has achieved a good screenings (41.62 dB sample PNSSI white face), a good electrical permittivity 4.97 to sample PNSSI and obtain an electrical conductivity of the order of $0.12 \times 10^{-17} \Omega \mathrm{cm}^{-1}$ for sample PNSSI and $0.11 \times 10^{-15} \Omega \mathrm{cm}^{-1}$ for the sample SSI.

In conclusion, the materials analyzed in this paper, are suitable to be used for the protection of the human factor of electromagnetic radiations are present in his life all the time, as it shows the increased level of attenuation of electromagnetic more than $40 \mathrm{~dB}$ lower values of electric permittivity and high levels of electrical conductivity.

\section{References}

1. RIAHI F.,DJAFER B., ABDELMALEK D., International J ournal of Polymeric Materials and Polymeric Biomaterials, 53, 2004, p. 143.

2. BOGUSH V., Journal of Optoelectronics and Advanced,3 (7), 2005, p.1635.

3.MAAN A.A. S., International J ournal of Current Engineering and Technology, 2014, p.2347.

4. MAAN A.A. S., Chemistry and Materials Research 6, (3), 2014, p.92. 5. MIRACLE B.D., DONALDSON L.S., Composites, 21, ASM Handbook, 2001.

6. IATAN R., ENACHESCU G.L., IAUNICU (STAMATE) I., POPA C.T., Journal of Engineering Studies and Research 19, (2), 2013 ,p.50.

7. BREZINKI S., RYBICKI T., MALINOWSKA G., KARBOW NIK I., RYBICKI E., SZUGAJEW L., Fiber \& Textiles in Eastern Europe, 17 (1), 2009, p.60.

8. BARBA A. A., LAMBERTI G., D'AMORE M., ACIERNO D., Polymeric Bulletin 57, 2006, p.587.
9. YUAN B. , BAO C., QIAN X. , SONG L. , TAI Q., LIEW K. M. , HU Y., Carbon 75, 2014,p. 178.

10. THOMASSIN J.M., JEROME C., PARDOEN T., BAILLY C., HUYNEN I., DETREMBLEUR C., Mater. Sci. Eng. R. 74, (7), 2013, p.211.

11. AHMAD M.S., ABDELAZEEZ M.K., ZIHLIV A., MARTUSCELLI E., RAGOSTA G., SCAFORA E., J .Mater.Sci, 25, 1990, p. 3080.

12. PALIGOVA M., VICAKOVA J., SAHA P., KRASLEK V., STEJ SKAL J., QUADRAT O., Physica A, 335, 2004, p.421.

13. LEE C.Y., SOMG H.G., JANG K.S., OH E.J., Synthetic Metals, 102, 1999, p.1346.

14. DUAN Y.P., LIU S.H., GUAN H.T., Science and technology of Advanced Materials, 6, 2005, p.513.

15. PINTEA J., MORARI C., BALAN I., CHITANU E., STOIAN E. V., Electromagnetic Compatibility-Electromagnetic Field, Research and Development in Romania, 2014,p.86.

16. MORARI C. , PINTEA J., NEAMTU J., BALAN I., Rev. Roum. Sci. Techn. - Electrotechn. et Energ., 53, 2008, p.123.

17. STOIAN E.V., RIZESCU C.Z., CHIPANU E., ANGHELINA V., POINESCU A.A., Electromagnetic pollution of environment, 2010, p.130-135.

18. STOIAN E.V., BRATU V., ENESCU M.C., POPESCU I.N., The Scientific Bulletin of Valahia University, Materials and Mechanics, 8, 2013, p.72. 19. NEAMTU J., GIURGIU L., KAPPEL W., MALAERU T., GEORGESCU G., PATROL E., ALECU V., Journal of Optoelectronics and Advanced Materials 6, (3), 2004, p.979.

20. ZHANG Y., FANG X.X., WEN B.Y., Chinese J ournal of Polymer Science, 33, (6), 2015, p.899.

21. WANG H.Q., ZHANG H.Y., ZHAO W.F., ZHANG W., CHEN, G.H., Compos. Sci. Technol., 68, (1), 2008

22. OH Y., CHUN K.Y., LEE E., KIM Y.J., BAIK S., J. Mater. Chem., 20, (18), 2010, p. 3579.

23. KUMAR R., DHAKATE S.R., SAINI P., MATHUR R.B., RSC Adv., 3,(13), 2013, p.4145.

24. KWON S., MA R., KIM U., CHOI H.R., BAIK S., Carbon, 68, 2014, p. 118.

25. YANG S.Y., LOZANO K., LOMELI A., FOLTZ H.D. ,JONES R., Composites Part A, 36, (5), 2005, p.691

26. ZHANG L., WANG L.B., SEE K.Y., MA J ., J. Mater. Sci., 48, (21), 2013, p 7757.

27. LI N., HUANG Y., DU F., HE X.B., LIN X., GAO H.J., MA Y.F., LI F.F., CHEN Y.S., EKLUND P.C., Nano Lett., 6, (6), 2006, p. 1141

28. ZHANG Z.M., YUE W., QIONG Li, LIANG-MIN Yu, JADRANKA T.S., ZHANG Li-Juan, Chinese Journal of Polymer Science, 31, (3), 2013, p.503.

29. CHARLES E., Virtual Chembook, Elmhurst, IL, USA, 2003.

30. J AGATHEESAN K., RAMASAMY A., DAS A., BASU A., Indian J ournal of Fibre and Research, 39, 2014, p.329.

31. RADU S., Introduction to Electromagnetic Compatibility, Gh. Asachi, Iasi, 1995.

32. STOIAN E.V., BRATU V., ANGHELINA F.V., POPESCU I.N., Advanced Materials Research 1114, 2015, p.76, Trans Tech Publications, Switzerland.

33. STOIAN E.V., Advanced Materials Research, 378-379, 2012, p.535, Trans Tech Publications, Switzerland.

Manuscript received: 14.12 .2018 